\title{
Simplifying the Measurement of Attitudes towards Autistic People
}

\author{
Paul H. P. Hanel ${ }^{1,2, *}$ (D) and Punit Shah ${ }^{1}$ \\ ${ }^{1}$ Department of Psychology, University of Bath, Bath, United Kingdom, and ${ }^{2}$ Department of Psychology, University of Essex, \\ Colchester, United Kingdom \\ *Corresponding author: Email: p.hanel@essex.ac.uk
}

(Received 30 January 2020; Revised 16 July 2020; Accepted 17 July 2020)

\begin{abstract}
There is growing interest in quantifying attitudes towards autistic people, however there is relatively little research on psychometric properties of the only existing measure and its ability to predict engagement with people with autism. To begin addressing these issues, we compared three scales measuring attitudes towards autistic people following the development of two new measures. Exploratory factor analysis, across two datasets, revealed that the factor-structure of an established 16-item scale is unclear. Further, its predictive validity of intended engagement with autistic people was comparable to our novel and psychometrically robust 1- and 4-item measures of attitudes towards autistic people. We therefore conclude that a 1- or 4-item scale is sufficient to measure general attitudes towards autistic people in future research. Equally, we propose that additional research is required to develop measures that are grounded in theoretical models of attitude formation and therefore distinguish between different components of attitudes.
\end{abstract}

Keywords: Autism; autistic; attitudes; measurement; neurodiversity

\section{Introduction}

Despite the impact non-autistic people have on the lives of autistic people, their attitudes towards people with autism are poorly understood. This is an important line of enquiry, given that these attitudes are likely to underpin behaviour towards autistic people (Kraus, 1995). Strikingly, however, there is only one measure of attitudes to autism, that is, the Societal Attitudes towards Autism Scale (SATAS; Flood et al., 2013), which appears to conflate attitudes, intentions, and behaviours towards autistic people. Accordingly, it is unclear if the SATAS has a unidimensional structure, given that some of its items concern affective dimensions of attitudes (e.g., "People with autism should not have children") whereas others refer to behaviours (e.g., "I would be uncomfortable hugging a person with autism"). This left us wondering if well-established attitude measures unrelated to autism (e.g., Armitage et al., 1999; Haddock et al., 1993) could be adapted to quantify attitudes towards autistic people.

\section{Objective}

The present research had two aims. First, using two datasets, we tested whether the SATAS (Flood et al., 2013) is unidimensional to address outstanding questions about its factor structure. Second, we developed 1- and 4-item measure of attitudes towards autistic people and explored if they had similar predictive validity to the 16-item SATAS. All things being equal, shorter measures are preferable as they

(C) The Author(s), 2020. Published by Cambridge University Press. This is an Open Access article, distributed under the terms of the Creative Commons Attribution licence (http://creativecommons.org/licenses/by/4.0/), which permits unrestricted re-use, distribution, and reproduction in any medium, provided the original work is properly cited. 
reduce participant fatigue and attrition, which are otherwise a threat to reliability and validity (Rammstedt \& Beierlein, 2014). All materials, code to reproduce the analyses, detailed results, and the data are openly accessible at https://osf.io/mf5bg

\section{Methods}

Participants were 135 undergraduate students, of which six failed two attention checks and were excluded $\left(M_{\text {age }}=19.86, S D=2.99 ; 103\right.$ women). They completed an online survey in exchange for course credits. Participants completed the SATAS (Flood et al., 2013) which had satisfactory internal reliability ( $\alpha=$ 0.76); a novel 1-item evaluative thermometer (based on Haddock et al., 1993) ranging between 0 and 100 to indicate their "overall evaluation of an autistic person"; and an adapted version of the 4-item attitude scale originally used by Armitage et al. (1999). The items all read "I see autistic people in general as..." and were answered on a scale ranging from -3 (bad, unfavourable, negative, unsatisfactory) to +3 (good, favourable, positive, satisfactory; $\alpha=0.92$ ). The order of the three scales was randomised. Finally, we measured intentions to engage with autistic people using a single item on a 1 (certainly not) to 7 (most certainly) point scale.

\section{Results}

A confirmatory factor analysis with robust standard errors and a Satorra-Bentler scaled test statistic revealed that the SATAS was not unidimensional, $\mathrm{CFI}=.78$, RMSEA $=.065$, that is, it was not measuring one construct. Instead, an exploratory factor analysis suggested the presence of three factors, similar to the pattern of results from a re-analysis of Flood et al.'s (2013) data ( $n=475$; see Supplemental Materials). In contrast, our 4 -item measure was unidimensional ( $\mathrm{CFI}=1.00, \mathrm{RMSEA}=0.00)$. The SATAS correlated positively with our attitude measures (Table 1 ) and all three measures were similarly predictive of the intention to engage with autistic people.

\section{Discussion}

We found that a 16-item measure of attitudes towards autistic people (Flood et al., 2013) is not unidimensional. Rather, it has several factors, and is therefore unlikely to selectively measure attitudes towards autistic people. It likely conflates measurement of attitudes, intentions, and behaviours towards autistic people, whereas our 1-item Attitudes towards Autism (ATA-1) measure is more parsimonious and robust. It also has greater practical utility and no worse predictive validity than longer measures, including our 4-item measure that was included in the present study to compare against the 1-item scale. Overall, we suggest that the ATA-1 should be used in future attitude-related autism research.

\section{Conclusion and Future Directions}

In conclusion, attitudes towards autistic people can be measured more precisely with a single item than a scale with a complex factor structure. A question on engagement with autistic people also validated our attitude measure and permitted comparison with the SATAS validation (Flood et al., 2013). It is possible

Table 1. Correlations between Attitudes towards and Intentions to Engage with Autistic People.

\begin{tabular}{lccc}
\hline & 1 & 2 & 3 \\
\hline 1 - 16-item SATAS & & & \\
\hline 2 - 1-item Evaluative Thermometer & $.41[.24, .56]^{\star \star \star}$ & $.70[.59, .79]^{\star \star \star}$ & \\
\hline 3 - 4-item Scale & $.37[.21, .51]^{\star \star \star}$ & $.24[.05, .41]^{\star \star}$ & $.20[.03, .36]^{\star}$ \\
\hline 4 - Intentions & $.27[.10, .42]^{\star \star}$ &
\end{tabular}

Note. ${ }^{\star} p<.05,{ }^{\star \star} p<.01,{ }^{\star \star \star} p<.001,95 \%$-Cls in brackets. 
that this question may not be measuring intended engagement with autistic people and instead tapping into general intentions to engage in volunteering activities. Future research will therefore benefit from testing if the ATA-1 is predictive of actual rather than intended engagement with autistic people. Our findings also need to be replicated in larger and non-student samples (Hanel \& Vione, 2016) and, if we are going to develop more comprehensive attitudes to autism measures, they should be grounded in theoretical and psychometric research on both autism and attitude formation (Breckler, 1984; Fazio, 1990; Shah et al., 2019). Nonetheless, the current study represents an important development in measurement of attitudes towards autistic people, which will benefit future research on understanding and changing (negative) attitudes towards people with autism.

Acknowledgements. We thank Betsy Morgan for sharing the raw data that was described in their paper (Flood et al., 2013). We also thank Alanna Shand for assistance with checking analyses and proof reading.

Conflict of Interest. The authors declare none.

Author's note. This research received no specific grant from any funding agency, commercial or not-for-profit sectors.

Author Contributions. PH and PS conceived and designed the study, PH conducted data collection, and PH and PS performed statistical analyses and wrote the article.

Data Availability Statement. All materials, R code to reproduce the analyses, detailed results, and the data are openly accessible at https://osf.io/mf5bg/?view_only=9579bd4c1aad4fd995a91b31ac3afae5

Ethics statement. The authors assert that all procedures contributing to this work comply with the ethical standards of the relevant national and institutional committees on human experimentation and with the Helsinki Declaration of 1975, as revised in 2008.

Supplementary Materials. To view supplementary material for this article, please visit http://dx.doi.org/10.1017/exp.2020.36.

\section{References}

Armitage, C. J., Armitage, C. J., Conner, M., Loach, J., \& Willetts, D. (1999). Different perceptions of control: Applying an extended theory of planned behavior to legal and illegal drug use. Basic and Applied Social Psychology, 21, 301-316. https:// doi.org/10.1207/S15324834BASP2104_4.

Breckler, S. J. (1984). Empirical validation of affect, behavior, and cognition as distinct components of attitude. Journal of Personality and Social Psychology, 47, 1191-1205. https://doi.org/10.1037/0022-3514.47.6.1191.

Fazio, R. H. (1990). Multiple processes by which attitudes guide behavior: The MODE model as an integrative framework. Advances in Experimental Social Psychology, 23, 74-109.

Flood, L. N., Bulgrin, A., \& Morgan, B. L. (2013). Piecing together the puzzle: Development of the Societal Attitudes towards Autism (SATA) scale. Journal of Research in Special Educational Needs, 2, 121-128. https://doi.org/10.1111/j.14713802.2011.01224.x.

Haddock, G., Zanna, M. P., \& Esses, V. M. (1993). Assessing the structure of prejudicial attitudes: The case of attitudes toward homosexuals. Journal of Personality and Social Psychology, 65, 1105. https://doi.org/10.1037/0022-3514.65.6.1105.

Hanel, P. H. P., \& Vione, K. C. (2016). Do student samples provide an accurate estimate of the general public?. PLOS ONE, 11, e0168354. https://doi.org/10.1371/journal.pone.0168354.

Kraus, S. J. (1995). Attitudes and the prediction of behavior: A meta-analysis of the empirical literature. Personality and Social Psychology Bulletin, 21, 58-75. https://doi.org/10.1177/0146167295211007.

Rammstedt, B., \& Beierlein, C. (2014). Can't we make it any shorter?. Journal of Individual Differences, 35, 212-220. https:// doi.org/10.1027/1614-0001/a000141.

Shah, P., Livingston, L. A., Callan, M. J., \& Player, L. (2019). Trait autism is a better predictor of empathy than alexithymia. Journal of Autism and Developmental Disorders, 49, 3956-3964. https://doi.org/10.1007/s10803-019-04080-3.

Cite this article: Hanel PHP, Shah P (2020). Simplifying the Measurement of Attitudes towards Autistic People Experimental Results, 1, e29, 1-6. https://doi.org/10.1017/exp.2020.36 


\title{
Peer Reviews
}

\author{
Reviewing editor: Dr. Stella Vlachou \\ Dublin City University, School of Psychology, Dublin, Ireland
}

This article has been accepted because it is deemed to be scientifically sound, has the correct controls, has appropriate methodology and is statistically valid, and met required revisions.

doi:10.1017/exp.2020.36.pr1

\section{Review 1: Simplifying the Measurement of Attitudes towards Autistic People}

Reviewer: Dr. Shu Yau (iD

Date of review: 15 July 2020

(c) The Author(s), 2020. Published by Cambridge University Press This is an Open Access article, distributed under the terms of the Creative Commons Attribution licence (http://creativecommons.org/licenses/by/4.0/), which permits unrestricted re-use, distribution, and reproduction in any medium, provided the original work is properly cited.

Conflict of interest statement. Reviewer declares none

Comments to the Author: This is a well written article that is clearly situated. The results are useful to the Autism research community, and is a welcome methodical improvement on previous measures quantifying attitudes towards autistic people, mostly in terms of saving time. Some minor comments - 1) Were the 3 tests presented in the same order and would counterbalancing have made a difference? 2) Sample size is mentioned in the supplementary material, would be useful to have in the Discussion 3) Could you make clearer what the rationale was for the 4-item scale as they seem to be asking essentially the same question? 4) The engagement question at the end may not necessarily be tapping 'intentions to engage'. Participant responses could be influenced by general perceptions of volunteering and time rather than their attitude towards autistic people. This can be explored in future extensions of the study, and mentioned in the limitations section.

\section{Score Card}

Presentation

Is the data presented in the most useful manner? (40\%)

Does the paper cite relevant and related articles appropriately? (30\%)

\section{Context}

Does the title suitably represent the article? (25\%)

Does the abstract correctly embody the content of the article? (25\%)

Does the introduction give appropriate context? (25\%)

Is the objective of the experiment clearly defined? (25\%) 
Are the limitations of the experiment as well as the contributions of the experiment clearly outlined? (20\%) 


\section{Review 2: Simplifying the Measurement of Attitudes towards Autistic People}

Reviewer: Dr. Elizabeth Sheppard (iD

Date of review: 25 June 2020

(C) The Author(s), 2020. Published by Cambridge University Press This is an Open Access article, distributed under the terms of the Creative Commons Attribution licence (http://creativecommons.org/licenses/by/4.0/), which permits unrestricted re-use, distribution, and reproduction in any medium, provided the original work is properly cited.

Conflict of interest statement. Reviewer declares none

Comments to the Author: This is a well executed study which provides information that I believe will be useful to researchers seeking to measure attitudes towards autistic people. The methodology and analysis appear sound and appropriate and the report contextualises and interprets the findings suitably. Although overall the manuscript is very well written and clear, I have just a couple of comments relating to typos/grammar used:

Page 4 line 68 refers to the terms "satisfaction" and "unsatisfaction" as part of the Armitage et al scale. The terms "satisfactory" and "unsatisfactory" were however used in the questionnaire (presented in the supplementary materials). Given that readers are likely to be more familiar with the satisfactory/ unsatisfactory wording, I would suggest changing this.

Page 5 line 92 refers to "autism-related autism research". I believe this should state "attitude-related autism research".

\section{Score Card}

Presentation

4.3

the article written in clear and proper English? (30\%)

Is the data presented in the most useful manner? (40\%)

Does the paper cite relevant and related articles appropriately? (30\%)

Does the title suitably represent the article? (25\%)

5.0

Does the abstract correctly embody the content of the article? (25\%)

Does the introduction give appropriate context? (25\%)

Is the objective of the experiment clearly defined? (25\%)

Analysis

Does the discussion adequately interpret the results presented? (40\%)

Is the conclusion consistent with the results and discussion? (40\%)

Are the limitations of the experiment as well as the contributions of the experiment clearly outlined? (20\%) 